\title{
Motion - Pancreatic endoscopy is useful for the pain of chronic pancreatitis: Arguments for the motion
}

\author{
Stanley M Branch MD
}

\begin{abstract}
S Branch. Motion - Pancreatic endoscopy is useful for the pain of chronic pancreatitis: Arguments for the motion. Can J Gastroenterol 2003;17(1):57-59.

Pain is the dominant clinical problem in patients with chronic pancreatitis. It can be due to pseudocysts, as well as strictures and stones in the pancreatic ducts. Most experts agree that obstruction could cause increased pressure within the main pancreatic duct or its branches, resulting in pain. Endoscopic therapy aims to alleviate pain by reducing the pressure within the ductal system and draining pseudocysts. Approaches vary according to the specific nature of the problem, and include transgastric, transduodenal and transpapillary stenting and drainage. Additional techniques for the removal of stones from the pancreatic duct include extracorporeal shockwave lithotripsy. Success rates for stone extraction and stenting of strictures are high in specialized centres that employ experienced endoscopists, but pain often recurs during long term follow-up. Complications include pancreatitis, bleeding, infection and perforation. In the case of pancreatic pseudocysts, percutaneous or even surgical drainage should be considered if septae or large amounts of debris are present within the lesion. This article describes the techniques, indications and results of endoscopic therapy of pancreatic lesions.
\end{abstract}

Key Words: Chronic pancreatitis; Pancreatic endoscopy
Hypothèse - La pancréatoscopie est utile pour soulager la douleur de la pancréatite chronique : Arguments en faveur de la motion

\begin{abstract}
RÉSUMÉ : La douleur constitue le problème clinique dominant des patients qui souffrent de pancréatite chronique. Elle peut être causée par des pseudo-kystes, ainsi que par des sténoses et des calculs dans les canaux pancréatiques. La plupart des experts s'accordent pour dire que l'obstruction ainsi causée pourrait faire augmenter la pression à l'intérieur du canal de Wirsung ou de ses rameaux, ce qui provoquerait la douleur. Le traitement endoscopique vise à soulager la douleur en réduisant la pression dans les canaux et en drainant les pseudo-kystes. Les méthodes varient en fonction de la nature particulière du problème et comprennent le drainage et la désobstruction transgastriques, transduodénaux et transpapillaires. On compte, parmi les autres techniques d'élimination des calculs des canaux pancréatiques, la lithotritie extracorporelle par ondes de choc. Les taux de réussite de l'élimination des calculs et de la désobstruction des sténoses sont élevés dans les centres spécialisés qui ont recours à des endoscopistes chevronnés, mais la douleur réapparaît souvent lors d'un suivi à long terme. Les complications de la pancréatoscopie comprennent la pancréatite, le saignement, l'infection et la perforation. Dans le cas des pseudo-kystes pancréatiques, on doit examiner la possibilité d'avoir recours à un drainage percutané ou même chirurgical en présence de septae ou d'une grande quantité de débris dans la lésion. Le présent article décrit les techniques, les indications et les résultats du traitement endoscopique des lésions pancréatiques.
\end{abstract}

Pain due to chronic pancreatitis is one of the most challenging situations that is routinely faced by gastroenterologists. Most of our therapeutic efforts for patients with chronic pancreatitis are directed at the control of pain (1-6). Medical therapy is the first approach, often with the help of a consultant in pain management, but surgery is often required for patients who fail to improve. This usually involves the removal of a damaged portion of the gland, drainage of a pseudocyst or drainage of the ductal system, which is based on the concept that pancreatic 'hypertension' is responsible for the patient's symptoms.

Surgery has yielded mixed results, with good relief in the early postoperative period in $80 \%$ to $90 \%$ of patients but poor long term results, with pain recurrence in up to one-half of patients. Our experience with surgery has been similar. More recently, endoscopic procedures that involve the decompres- sion of the pancreatic duct have become popular. As with surgery, the goal has been to relieve outflow obstruction of the pancreatic duct. Although there have been no randomized studies comparing endoscopic with surgical treatment of chronic pancreatitis, the endoscopic approach is attractive because it is less invasive and has less morbidity. It does not exclude future surgery, and some authorities have suggested that success with endoscopy may predict a favourable response to surgical drainage. Therapeutic endoscopic retrograde pancreatography has been used mainly for strictures and stones in the main pancreatic duct and pseudocysts.

\section{PANCREATIC DUCTAL STRICTURES}

Strictures of the main pancreatic duct frequently occur in cases of chronic pancreatitis. While it is difficult to determine

This article was originally presented at a symposium entitled, "Controversies in Gastroenterology", sponsored by Axcam Pharma, Toronto, Ontario, April 8 to 10, 2002

Division of Gastroenterology, Duke University Medical Center, Durham North Carolina, USA

Correspondence: Dr Stanley M Branch, Division of Gastroenterology, Duke University Medical Center, 04212 Hosptial South, Box 3662

Medical Center, Durham, North Carolina 27710-001, USA. Telephone 919-684-3787, fax 919-681-8955 
whether a particular stricture is the cause of pain, the most common endoscopic approach has been to treat patients who have a nonmalignant (by cytology) dominant main duct stricture with upstream ductal dilatation. A 7- or 10-Fr stent is inserted in a similar fashion to a biliary stent. Very tight strictures require dilation before stent placement. The following important points should be remembered: the stent diameter should not exceed the diameter of the stent downstream from the stricture; the stent should not be placed in such a way that the tip is abutting on or torqued into the duct wall; and one must carefully choose the shape and length of the stent so as to have the best fit and limit injury to the duct.

Outcome data from stent placement in various studies have been confusing. In an American Society for Gastrointestinal Endoscopy review of this topic, technical success rates of $82 \%$ to $100 \%$ have been quoted (1). These studies also found that $63 \%$ of patients reported some improvement of symptoms, complications occurred in $19 \%$ and mortality was $1 \%$. These data are suspect, however, because some, but not all, patients subsequently underwent stent removal. The appropriate 'duration' of stenting is unclear: some stents are retained for one or two years without complication, whereas others occlude within weeks. Moreover, the duration of follow-up and the outcome measurements varied among different studies. Some patients underwent additional procedures, such as sphincterotomy and/or stone extraction. Success rates also seem to vary with the cause of pancreatitis, because some authors suggest that chronic alcoholics do not respond as favourably $(2,4)$. Complications include stent occlusion (causing pain or pancreatitis), stent migration, infection, duct perforation ,and changes to the duct and parenchyma.

While further study is needed, a trial of pancreatic duct stenting seems to be appropriate for patients with chronic pancreatitis and poorly responsive pain who exhibit a stricture of the main pancreatic duct and upstream ductal dilation.

\section{PANCREATIC DUCTAL STONES}

Pancreatic calcifications frequently complicate chronic pancreatitis and usually represent ductal calculi. The most important question in such cases is whether the stone is merely incidental or if it is the cause of symptoms. Several authorities believe that the pain is due to ductal obstruction, and have found that surgical or endoscopic procedures to remove pancreatic duct stones result in the alleviation of symptoms. This appears to be especially true for patients with stones in the main pancreatic duct, associated with upstream dilation.

Endoscopic treatment usually involves pancreatic sphincterotomy followed by removal of the stone(s) with balloons or baskets. It is not easy to remove ductal stones. A stricture frequently occurs near the papilla and must be dilated to allow stone extraction. Other impediments to stone removal include partial impaction of stones in side branches of the pancreatic duct, 'exiting' duct diameter that is smaller than that of the stone and the inability to pass a guidewire beyond the stone or duct angle. In a compilation of clinical series from centres with expert endoscopists, complete stone extraction was achieved in $63 \%$ of cases, symptoms were relieved in $74 \%$, and complications occurred in $9 \%$, mainly from pancreatitis (1).
Extracorporeal shockwave lithotripsy has been used for some patients with large stones that cannot be removed with routine endoscopic techniques. Before extracorporeal shockwave lithotripsy, pancreatic sphincterotomy is usually performed and either a nasopancreatic tube is left in place to help visualize the stones with contrast injection or the stones are identified using ultrasound. After lithotripsy, the stones are cleared by repeat endoscopic retrograde pancreatography. It has been reported that stone clearance was achieved in 59\% of cases, symptomatic improvement occurred in $72 \%$ at 18 months, the complication rate was $19 \%$, and no deaths could be attributed to the procedure (5). Dissolution techniques have also been tried, but this does not currently seem to be practical, because no solvents exist that dissolve stones rapidly.

\section{PANCREATIC PSEUDOCYSTS}

Pancreatic pseudocysts should be drained, if possible, in symptomatic patients. Endoscopic drainage of these collections is an increasingly popular procedure. Several investigators have reported success rates of $65 \%$ to $95 \%$, with complication rates of $10 \%$ to $35 \%(1,3,6)$. Complications include infection, hemorrhage, perforation and pancreatitis.

At Duke University, our approach is to drain the pseudocyst through the 'transgut' (transgastric or transduodenal) approach, especially if the lesion abuts these structures. Transgut drainage is usually preceded by a needle puncture to verify location (with fluid aspiration or contrast injection). A tract to the pseudocyst is created by diathermy needle cautery, followed by the placement of a guidewire, over which balloon dilation is performed and one or more double pigtail stents are inserted. We usually dilate the tract to $12 \mathrm{~mm}$ diameter. Computerized tomography or ultrasound imaging should be repeated in two to three weeks, and the stent(s) should be removed if the pseudocyst has resolved. Bleeding is the most worrisome complication, and is more likely if there is thrombosis of the splenic or portal veins. Most experts require that two criteria be satisfied before transgut drainage is undertaken: there must be an obvious indentation of the luminal wall by the pseudocyst, and the transmural distance to the pseudocyst, measured by computerized tomography or ultrasound, should be no greater than $1 \mathrm{~cm}$.

Our current practice is to perform endoscopic ultrasonography to help localize and mark the pseudocyst and evaluate its contents, and to identify any vascular structures that may be in the way of drainage. If there are septae or a large amount of necrotic debris in the pseudocyst, then either a percutaneous approach, which allows easier flushing of debris, or surgery should be considered.

The transpapillary approach involves placing the stent into the pseudocyst either directly through the pancreatic duct or by traversing the ductal communication. Although this technique is less likely to cause bleeding than the transgut approach, it is associated with an increased risk of infection. This is occasionally combined with percutaneous drainage. Transpapillary drainage is appropriate if the disruption occurs in a side branch of the main pancreatic duct, or occasionally if there is leakage from the end of the duct. Another approach, such as surgical drainage, should be considered if there is a large communication with the pseudocyst or significant debris 
within the lesion, or if stent placement does not appear to be optimal.

Pancreatic duct strictures make endoscopic treatment more difficult, because 'downstream' obstruction leads to the persistence or recurrence of the pseudocyst. It is important to use the shortest possible stent and to remove the stent after the pseudocyst resolves, to minimize ductal injury. These considerations may be less important, however, in patients with chronic pancreatitis.

While endopancreatic therapy appears to be of value in the treatment of pain associated with chronic pancreatitis, prospective data are still needed to validate this technique. For now, most experts recommend that these techniques be performed only by experienced endoscopists in centres that can deal with any complications.

\section{REFERENCES}

1. American Society for Gastrointestinal Endoscopy. Endoscopic therapy of chronic pancreatitis. Gastrointest Endosc 2000;52:843-8.

2. Boerma D, Huibregtse K, Gulik TM, Rauws EA, Obertop H, Gouma DJ. Long-term outcome of endoscopic stent placement for chronic pancreatitis associated with pancreas divisum. Endoscopy 2000;32:452-6.

3. Walters DA, Geenen JE. Current role of endoscopic retrograde cholangiopancreatography in the management of benign pancreatic disease. Endoscopy 1998;30:174-81.

4. Norton ID, Peterson BT. Interventional treatment of acute and chronic pancreatitis. Endoscopic procedures. Surg Clin North Am 1999;79:895-911.

5. Kozarek RA, Traverso LW. Endotherapy for chronic pancreatitis. Int J Pancreatol 1996;19:93-102.

6. Godil A, Chen YK. Endoscopic management of benign pancreatic disease. Pancreas 2000;20:1-13. 


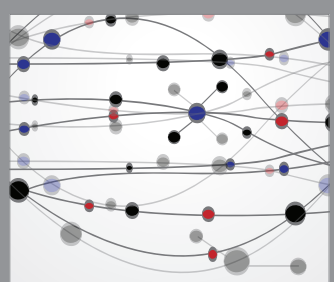

The Scientific World Journal
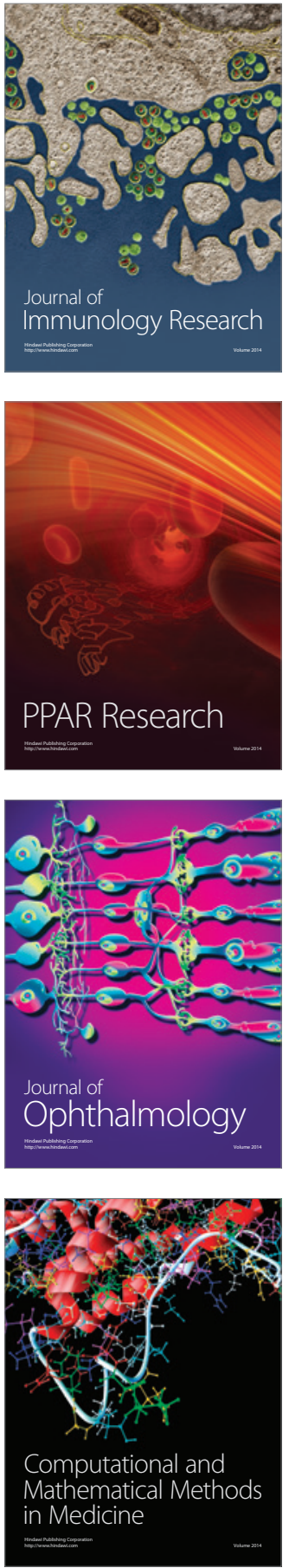

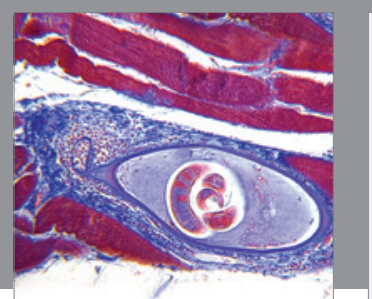

Gastroenterology Research and Practice

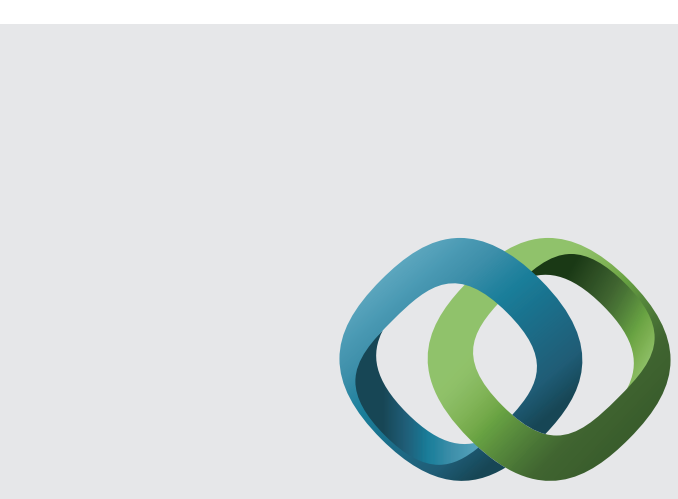

\section{Hindawi}

Submit your manuscripts at

http://www.hindawi.com
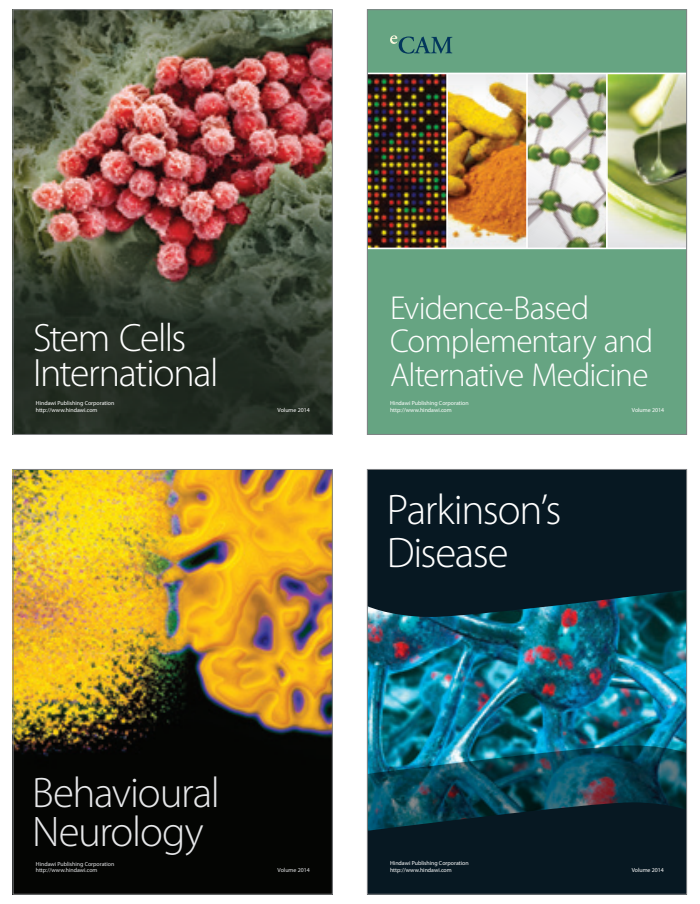
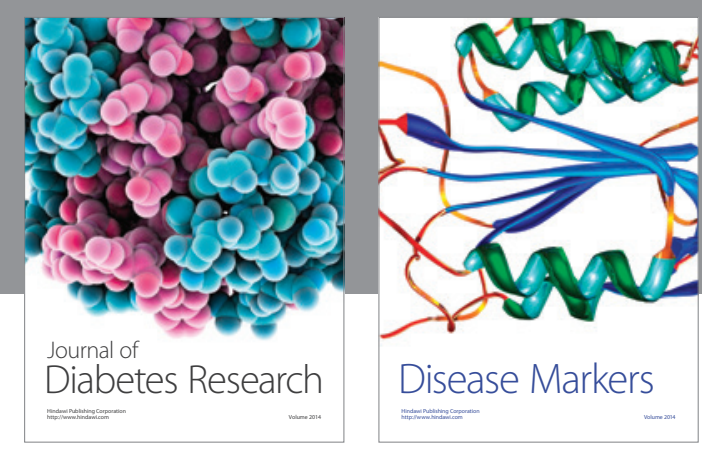

Disease Markers
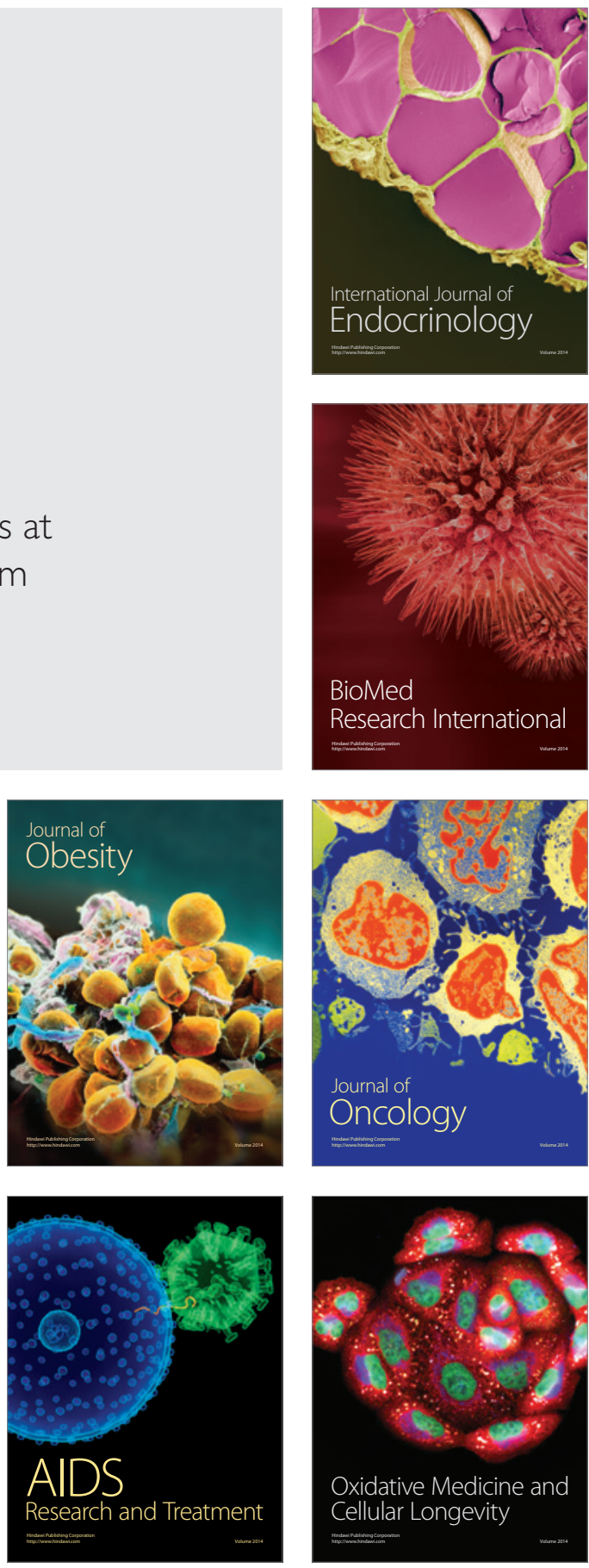